\title{
Research on Teaching Reform and Practice in Hydraulic Transmission
}

\author{
Jian $\mathrm{Li}^{1,}$, , Liujin Cai ${ }^{1, b^{*}}$ and Haoyi Ma ${ }^{1, c}$ \\ ${ }^{1}$ School of Mechatronic Engineering, Henan University of Science and Technology, Luoyang, \\ 471003, China \\ aly-sword@163.com, byycailj@163.com, cyymahaoyi@163.com \\ *The corresponding author
}

Keywords: Hydraulic transmission; Teaching reform and practice; Innovative spirit; Practical ability

\begin{abstract}
Hydraulic transmission technology is a combination of fluid mechanics, mechanical design, mechanical principles, electrical and electronic, automatic control and other aspects of the comprehensive knowledge of the curriculum. In order to cultivate students' innovative spirit and practical ability, this paper puts forward the specific reform schemes of hydraulic transmission course, from the following three aspects: teaching contents, teaching methods and assessment methods described in detail for the "hydraulic transmission" curriculum reform measures. Teaching practice shows that the reform measures have obtained good teaching effect.
\end{abstract}

\section{Introduction}

Hydraulic transmission technology is a combination of fluid mechanics, mechanical design, mechanical principles, electrical and electronic, automatic control and other aspects of the comprehensive knowledge of the curriculum. Because of many characteristics of hydraulic transmission with mechanical transmission and electric drive are irreplaceable, different fields of the hydraulic transmission technology is widely used in industrial production of engineering machinery, CNC machining centers, automated production lines, which is one of the most widely industrial application of the basic technology. In order to realize the transformation from a big manufacturing country to a powerful manufacturing country, it has become the consensus of the whole society to develop the hydraulic transmission technology to improve the level of industrial development in our country. At present, the wide application of hydraulic transmission technology in various fields makes the demand of relevant technical personnel increase rapidly. The course of "hydraulic transmission" has become an urgent need for the development of mechanical engineering. At the same time, because of the comprehensive and high engineering characteristics of "hydraulic transmission", through learning this course, students will contribute to combine the theory and practice of mechanical engineering field, which improves students' innovative spirit and practical ability.

As a basic course of mechanical engineering, the course of "hydraulic transmission" has been established for decades in the history of Henan University of Science and Technology. However, the teaching effect was not ideal in the past because of the indoctrination teaching method. In addition, the teaching content was mainly based on the theory teaching, and it was not close to the engineering practice, especially introduced the hydraulic transmission technology that represented the development trend and direction of development of new hydraulic components and devices were less, the content of teaching was lagging behind the rapid development of hydraulic transmission technology, lack of training and education of students' innovation spirit and practice ability. This situation obviously can not meet the requirements of the new era of national training of hydraulic technology personnel, we must reform the teaching of "hydraulic transmission". This article from the teaching content, teaching methods and assessment methods in three aspects of our school "hydraulic transmission" curriculum reform and practice to do a presentation. 


\section{Reform of Teaching Content}

According to the orientation of teaching and researching local colleges and the aim of cultivating talents of industrial application in our school, we formulate the teaching goal of "hydraulic transmission" curriculum is to enable students to master the basic theoretical knowledge of hydraulic transmission, cultivate students' ability to solve practical engineering problems of hydraulic system. According to the teaching goal, we put forward the guiding ideology of the curriculum content reform of "dilution theory derivation and focusing on engineering application". The teaching content of "hydraulic transmission" can be divided into three parts: basic theory, hydraulic components, hydraulic basic circuit and typical system.

Fluid mechanics as the basic theory of "hydraulic transmission" is one of the difficulties in the course of hydraulic transmission. This part involves many basic concepts and principles of hydraulic transmission theory, the theory is deep and abstract so that it is more difficult for students to understand and master. According to the training objectives of our school training application of hydraulic technology talents, we redesigned the teaching contents, the contents of materials in hydraulic transmission fluid mechanics theory of strong compression, introduces the principle of the hydraulic system, the hydraulic system pressure, flow, flow, pressure loss and other basic concepts, nature and the selection of hydraulic oil, as well as the three basic equations of fluid dynamics etc.. During the explanation, but the pursuit of more theoretical formula is derived, and will focus on how to practice in the theoretical formula, highlight the "knowledge". This can make students understand the theory of the sequence of events and how to carry out the engineering application, but also avoid the derivation in the teaching process of tedious formula, improve the students' learning interest and effect.

Hydraulic component part is one of the main content of the course, this part mainly combines mechanical drawing, mechanical principle has been learned, focuses on the hydraulic pump, hydraulic cylinder, hydraulic control valve of the working principle, structure characteristics and main parameters. In the teaching we should pay attention to the connection engineering example describes the use of hydraulic components and common fault analysis, and through the hydraulic component assembly experiment to further enhance the students on the hydraulic components of the structure, selection, use and maintenance ability. In the teaching of hydraulic components design analysis and calculation of the content such as deleting related to performance, but the simple of electro-hydraulic proportional valve, hydraulic servo valve and other new technology, to enable students to understand the latest trends and direction of development of hydraulic technology, broaden their horizons, cultivate interest.

The basic hydraulic circuit system and typical part is the comprehensive application of hydraulic transmission course content, teaching is the focus of the direction control, pressure control and speed control of the three basic circuit composition, characteristics and application, common powerslider hydraulic grinder and typical hydraulic system in engineering as an example, to guide the students to master the method the hydraulic system of mechanical and electrical equipment and steps of reading map. Through the experiment of hydraulic basic circuit, the theory and practice of the students are combined, and the ability of analyzing the hydraulic circuit is analyzed. At the same time, it introduces the use of common hydraulic equipment, common faults and equipment maintenance methods, and trains the students' engineering practice ability. For the design and calculation of hydraulic system and so on, the application is less.

\section{Reform of Teaching Methods}

Using Multimedia Courseware to Improve Teaching Effect. "Hydraulic transmission" in the course of a large number of hydraulic components, hydraulic circuit structure working principle to explain, using charts, the traditional model of teaching aid and so can not only reflect the relation between the composition of the specific structure of hydraulic components, each component of the action process cannot be described during the operation of hydraulic system, teachers and students feel in time-consuming. The content of image is not boring, the teaching effect is not ideal. When 
making courseware for teaching the use of multimedia technology, is to be able to present the content of classroom teaching by graphics, text, sound and animation integrated form vividly in front of the students get a better teaching effect. For example, the structure of the complex hydraulic components, the students only look at two-dimensional plane drawings, it is difficult to accurately understand the composition and assembly of hydraulic components. When the Solidworks 3D mechanical design software to describe the hydraulic components, hydraulic components can not only display each clear part of the structure, but also can put out all parts of the assembly relationship intuitive reaction, it is easy for students to understand and accept. As for the working process of the hydraulic circuit, through the flash animation, can be the direction of fluid flow, the elements of action and state vividly and clearly demonstrated, deepen the students' understanding and memory, greatly enhance the vitality and enthusiasm of the students teaching. The multimedia courseware is convenient for students to deepen their understanding of the teaching contents in the after-school review, made many achievements.

Improving Experimental Teaching Methods and Cultivating Students' Engineering Ability. As a strong professional basic course of a practice, the experiment of hydraulic transmission course is designed to consolidate and deepen the theoretical knowledge of learning, enhance practical ability, to enable students to master the general selection of hydraulic components, hydraulic system design methods, ability of hydraulic system engineering some practical problems, troubleshooting. Therefore, from the theory and Practice on the cultivation of students, enhance the ability of the point of view of engineering application, we improved the experiment content, hand cut part of the theory of experimental verification and performance test, and increase the students hands-on assembly experiment of hydraulic components of the students direct and comprehensive understanding of the hydraulic valve, hydraulic pump the structure and composition of. On the other hand, the hydraulic circuit and hydraulic system assembly and debugging of open experiments, the teachers only presents experimental contents and requirements by the students according to the knowledge to develop the experiment scheme, selection of hydraulic components, hydraulic circuit connection, find problems and solve problems independently. Through the improvement of the experimental method, the students arouse their interest in learning, the consciousness of active thinking and active participation has been enhanced, and the ability of independent analysis, problem solving and engineering awareness has been improved.

Enrich Teaching Methods to Improve Students' Learning Effect. Many of the concepts of hydraulic transmission in the abstract, students often feel difficult in learning, in order to help students understand the hydraulic transmission theory, the proper use of "analogy method, control method, research method of various teaching methods in the teaching process, can mobilize the enthusiasm of the students, to stimulate interest in learning, received twice effect. For example, by analogy, the hydraulic system and the students are familiar with the basic concepts of "Electrical Engineering" analogy, the students will translate the abstract knowledge into the hydraulic system is easy to understand the content, improve the interest and efficiency of learning. And as the symbol for the relief valve, pressure relief valve, sequence valve and other hydraulic components with similar functions but different functions, the list of methods that contrast the respective structure principle, function symbols, characteristics and applicable occasions corresponding explanation, not only is convenient for students to understand, distinguish, and focused, clear, easy to master. In the learning process, some of the error prone students special discussion, let students talk about the questions discussed ideas, methods and ideas to solve the problem, this way not only can promote students thinking, dare to give independent opinions, but also to cultivate students' innovation consciousness and creative ability.

\section{Optimized Examination Methods}

Examination is an important means to judge the learning effect of students and the quality of teaching. In order to improve the students' active learning awareness and knowledge of the comprehensive ability, from theoretical knowledge examination, experiment ability, learning attitude and other aspects of student achievement assessment, instead of only the final written 
examination method. Theoretical knowledge examination focuses on assessing students' understanding of basic theory and concepts, accounting for $70 \%$ of the total score. The ability of experiment to reflect the students' mastery of theoretical knowledge and the ability of comprehensive application, which accounted for $20 \%$ of the total score. Students usually participate in the school situation, the completion of the work situation and the attendance rate of the learning attitude reflected in the total score of $10 \%$. Through the optimization of the assessment method, it not only enhances the initiative of students, but also creates favorable conditions for improving students' practical ability.

\section{Summary}

As one of the basic courses of mechanical specialty in our college, "hydraulic transmission" plays an important role in training students' professional knowledge of the comprehensive application ability, practical ability and innovation ability. According to my school orientation and talent training target, puts forward some teaching reform proposals and suggestions in three aspects of "hydraulic transmission" course in the teaching content, teaching methods and assessment methods, and have achieved good results in teaching practice, has been popular with students. The next step will further explore how to make the students as much as possible to contact the actual project, improve the engineering application ability.

\section{References}

[1] F. L. Xu, Y. M. Chen: hydraulic and pneumatic transmission (China Machine Press, China 2007)(In Chinese)

[2] P.H. Gu, W. L. Hu and P. Lin: Research in Higher Education of Engineering, (2014)No.1, p.27.(In Chinese)

[3] Y. G. Yang, B. Meng and W. N Wang: Research in Higher Education of Engineering, (2015)No.6, p.24.(In Chinese)

[4] Y. Song, S. Hu and Z. Y. Yu: Experimental Technology and Management, Vol. 33 (2016)No.2, p.4.(In Chinese)

[5] X.Q. Chen, G. L. Dai: Journal of Zhejiang University of Technology, Vol. 14 (2015)No.4, p.464.(In Chinese)

[6] Information on http:// en. Wikipedia. Org/wiki/Outcome-based-education \# United states.

[7] B. Liu, M. Zhou and C. S. Tong: Experimental Technology and Management, Vol. 33 (2016)No.3, p.197.(In Chinese)

[8] Q. Feng: Journal of Anhui Polytechnic University, Vol. 31 (2016)No.3, p.81.(In Chinese) 